\title{
Revisiting HIV-1 uncoating
}

Nathalie Arhel

\begin{abstract}
HIV uncoating is defined as the loss of viral capsid that occurs within the cytoplasm of infected cells before entry of the viral genome into the nucleus. It is an obligatory step of HIV-1 early infection and accompanies the transition between reverse transcription complexes (RTCS), in which reverse transcription occurs, and pre-integration complexes (PICs), which are competent to integrate into the host genome. The study of the nature and timing of HIV-1 uncoating has been paved with difficulties, particularly as a result of the vulnerability of the capsid assembly to experimental manipulation. Nevertheless, recent studies of capsid structure, retroviral restriction and mechanisms of nuclear import, as well as the recent expansion of technical advances in genome-wide studies and cell imagery approaches, have substantially changed our understanding of HIV uncoating. Although early work suggested that uncoating occurs immediately following viral entry in the cell, thus attributing a trivial role for the capsid in infected cells, recent data suggest that uncoating occurs several hours later and that capsid has an all-important role in the cell that it infects: for transport towards the nucleus, reverse transcription and nuclear import. Knowing that uncoating occurs at a later stage suggests that the viral capsid interacts extensively with the cytoskeleton and other cytoplasmic components during its transport to the nucleus, which leads to a considerable reassessment of our efforts to identify potential therapeutic targets for HIV therapy. This review discusses our current understanding of HIV uncoating, the functional interplay between infectivity and timely uncoating, as well as exposing the appropriate methods to study uncoating and addressing the many questions that remain unanswered.
\end{abstract}

\section{Structure of mature HIV-1 capsid and its importance at early stages of infection}

The mature HIV-1 capsid, also called HIV-1 core, is a highly organised macromolecular assembly, formed within newly released virions upon proteolytic cleavage of the precursor p55Gag polyprotein by the viral protease which generates the cleavage product CA (also called capsid or p24). Rather confusingly, the term capsid refers both to the conical multimeric structure and to the CA monomers that constitute the cone. Therefore, to avoid all confusion, the terms "capsid" and "core" are preferred for reference to the conical structure and monomers are referred to as "CA". Negative staining and cryo-electron microscopy of authentic mature particles or isolated mature HIV-1 cores reveal that capsids have an intriguing conical shape, with a relatively consistent length of 100-120 nm [1-4] (Figure 1). The diameter of the wide end of the capsid cone (50-60 $\mathrm{nm})$ and the angle at the tip of the cone (18-24.) may vary

Correspondence: nathalie.arhel@pasteur.fr

Department of Virology, URA3015, Institut Pasteur, 25-28 rue du Dr. Roux, 75015 Paris, France and lead to capsids with apparent heterogeneity of shape (bullet shape, cylindrical forms).

The intrinsic properties of the HIV-1 capsid, such as its poor stability or asymmetry, have made it particularly difficult to explore the detailed structure of mature cores isolated from disrupted virions. However, recombinant CA can spontaneously assemble in vitro into cones and structures analogous to authentic HIV-1 capsids [5] and much of the valuable information we have on the shape and underlying molecular structures of the capsid derive from core-like structures obtained from in vitro $\mathrm{CA}$ assembly reactions. These have shown that despite its macromolecular asymmetry, the HIV-1 capsid is assembled with a high degree of organisation as a fullerene cone, a structure with hexagonal lattice symmetry that is capped at both ends $[5,6]$. The HIV-1 capsid is made up of ca. 1,500 CA monomers, which assemble into 250 hexameric rings through NTD-NTD (N-terminal domain) interactions, which are themselves linked into a hexagonal lattice through CTD-CTD (C-terminal domain) interactions $[7,8]$. The hexagonal lattice is curved into a cone through subunit mobility [8] and is 


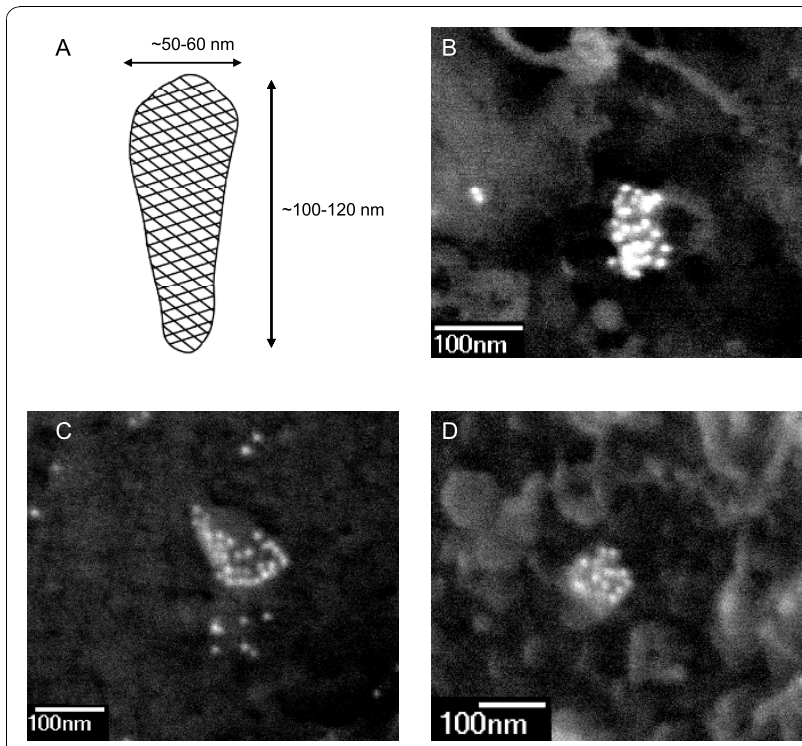

Figure 1 Scanning electron microscopy imaging of HIV-1 capsids in the cytoplasm and at the nuclear membrane of infected cells. (A) Schematic representation of the mature HIV-1 capsid shell. The HIV-1 capsid is an assembly of approximately 1,500 CA monomers arranged into a hexagonal array of hexamers. Dimensions are derived from microscopy observations of mature virions or isolated cores. (B-D) Images show the backscattered gold signal corresponding to specific labelling with a mouse monoclonal anti-p24 antibody (183-H12-5C AIDS Reagent Program) followed with goat anti-mouse lgG H\&L conjugated $10 \mathrm{~nm}$ gold (British Biocell International) in HIV-1 infected P4-CCR5 cells. HIV-1 capsids are typically conical- or cylindrical-shaped, ca 100-150 nm long, and heavily labelled with 10-30 immunogold particles. The bulk of antibodies likely induces some distortions in size and shape of capsids. In panels B and D, capsids are located at the nuclear membrane: nuclear pore complexes appear as bright rings with dark lumen.

capped by exactly 12 pentameric rings, 7 at the wide end and 5 at the narrow end of the cone [5].

The capsid contains the viral genome (two single stranded RNA molecules), some viral proteins (CA, nucleocapsid (NC), reverse transcriptase (RT), integrase (IN), Vpr) and numerous cellular proteins, such as Cyclophilin A and APOBEC3G [9]. Its main function is to organise and contain the viral genome for optimal delivery in target cells and efficient reverse transcription, which together contribute to effective replication in the new host cell. The capsid cone is absolutely essential for infection since mutations of protease cleavage sites in Gag, or inhibitors of Gag processing, produce immature virions and abolish HIV-1 infectivity [10-13]. Furthermore, point mutations that lead to hyperstable or unstable capsids, or to capsids with aberrant morphologies, lead almost systematically to reduced infectivity [14], indicating that the shape and stability of the capsid are also critical for HIV-1 infectivity.

\section{The necessity of uncoating for HIV-1 and other lentiviruses}

HIV-1 and other lentiviruses are unique among orthoretroviruses in their ability to replicate efficiently in metabolically active non-dividing cells $[15,16]$ as a result of the active nuclear import of their genome across the nuclear membrane of interphasic nuclei [17]. Retroviruses such as the Murine Leukaemia Virus (MLV) gain access to the nuclear chromatin following the disassembly of the nuclear membrane that occurs during mitosis [18]. For such retroviruses, evidence suggests that the viral capsid accompanies the viral genome into the nuclear compartment and participates in interaction with the chromatin [19] indicating that uncoating is not required prior to nuclear import.

HIV and other lentiviruses enter the nuclei via the nuclear pore; and, although commonly assumed, it is by no means certain that they can use an alternative route of entry during mitosis. Indeed, the replication of certain lentiviruses (such as EIAV, CAEV and VISNA) is entirely limited to macrophages, which do not divide. In the case of HIV-1, which infects cycling CD4+ T cells in addition to macrophages, a mitosis-independent nuclear import in cycling cells has been reported [20]. Furthermore, a genome-wide RNA interference-based screen comparing HIV-1 and MLV infections identified unique nuclear import factors for HIV-1 even though the study was carried out in cycling cells [21]. In addition, HIV-1 mutants with a nuclear import defect in cell cycle-arrested cells often maintain this defect in cycling cells [22-25]. Finally, the assumption that HIV-1 might passively gain access to the chromatin upon mitosis, if based on the belief that cytoplasmic and nuclear contents mix homogeneously throughout mitosis, is not valid. Indeed, evidence suggests that mitotic cells maintain spatial information through gradients, such as the RanGTP gradient that surrounds chromatin $[26,27]$. Taken together, it is probable that HIV-1 enters nuclei only through the nuclear pore whether cells divide or not.

The dependency of lentiviruses on non-dividing cells for in vivo transmission and persistence and the resulting necessity to enter the nucleus through the nuclear pore impose an uncoating step because the diameter of the viral capsid (up to $60 \mathrm{~nm}$ wide) exceeds that of the nuclear pore $(\sim 30 \mathrm{~nm})$. Consistent with this notion, previous work has reported a substantial difference in mass between cytoplasmic and nuclear HIV-1 complexes $[28,29]$ and the absence of CA within pre-integration complexes [30,31].

\section{Where and when does uncoating occur?}

Although most agree that uncoating occurs after fusiondependent entry in the cytoplasm and before nuclear 
import, the field remains divided as to the precise moment and location for this event. Indeed, the extent of the role of HIV-1 capsid at early stages of infection is still a matter of debate. In a first model, the viral capsid is disassembled close to the plasma membrane immediately following fusion into the cytoplasm and most CA is dissociated from the HIV-1 nucleoprotein complex [32-35]. Uncoating is required for formation of the reverse transcription complex (RTC) and is likely triggered by the sudden change in environment in which the viral complex finds itself, or possibly by the loss of high concentrations of free CA present in virions and responsible for maintaining metastable cores [36]. In this model, the absence of significant amounts of CA within intracellular HIV-1 complexes soon after inoculation [28,29,37-39] and the inability to detect capsids in the cytoplasm of infected cells using transmission electron microscopy (TEM) [40] led to the conclusion that the primary function of HIV-1 capsid is to deliver the viral genome into the cytoplasm, after which it can and must be discarded for productive infection to proceed, although it is not excluded that initial disassembly is partial [32-35].

A second model proposes that capsid remains intact for some time post-entry, at least for the initiation of reverse transcription, and that uncoating occurs gradually during transport towards the nucleus and reverse transcription [41]. In this model, uncoating is promoted in response to multiple successive changes in the cellular environment, sequential contact with different cell factors, and through the molecular rearrangements that accompany reverse transcription, thus triggering progressive or stepwise conformational changes and disassembly. In support of this hypothesis are studies that report a broad range of different sizes and shapes for cytoplasmic HIV-1, both greater and smaller than mature extracellular cores, suggesting a complex series of transformations accompanying reverse transcription and transport to the nucleus [39,41-43] (although it cannot be excluded that the observed variations are due to the preparation or isolation protocol [44]), immunofluorescent microscopy showing association of CA with RTCs [42], and the demonstration that capsids with increased or decreased core stability has impaired reverse transcription [14].

A third model, which we favour, proposes that capsids remain intact until HIV-1 incoming complexes reach the nuclear membrane and that uncoating occurs at the nuclear pore upon completion of reverse transcription. In this model, the HIV-1 capsid is all-important for maintaining a high stoichiometry of HIV-1 reverse transcriptase enzyme relative to the viral genome during reverse transcription to counteract its tendency to dissociate from its template [45], since dilution of reverse transcriptase in the cytoplasm would lead to highly ineffective reverse transcription. While it organises the HIV-1 viral genome and proteins, it offers no impermeable environment from small macromolecules of the cytoplasm: the capsid lattice is an open structure, with inter-ring spacings of up to $10 \mathrm{~nm}$ [6], which allow small macromolecules, such as nucleotide triphosphates and indeed reverse transcriptase inhibitors, to access the reverse transcription complex in the cytoplasm of infected cells. While the first model proposes that uncoating (at the plasma membrane) is required to trigger viral reverse transcription, this third model suggests that it is the successful completion of reverse transcription (at the nuclear pore) that triggers uncoating.

Recent evidence suggests that the integrity and timely disassembly of the HIV-1 capsid are essential for routing to the nuclear compartment, reverse transcription and successful nuclear import [14,29,46-48]. For this reason, there is an increasing appeal to determine up to which point the viral capsid is required for infection and at which point in space and time it is disassembled.

\section{Uncoating accompanies the conversion of RTCs into pre-integration complexes (PICs)}

In early replication, incoming HIV-1 is referred to either as an RTC or as a PIC. The literature is divided as to the nature and location in the cell of HIV-1 RTCs and PICs, and most importantly as to the presence or lack of capsid in these complexes. RTCs are simply defined as HIV-1 complexes that undergo reverse transcription, during which they convert their single-stranded positive RNA viral genome into double-stranded DNA [49,50] (Figure 2). The RTC genomes are thus either RNA or RNA-DNA intermediates of reverse transcription. In contrast, PICs no longer contain any RNA but only the double-stranded DNA. PICs are per definition integration-competent HIV-1 complexes and can integrate efficiently into a target DNA in vitro $[51,52]$. They are formed in the cytoplasm upon synthesis of full-length viral DNA and then translocate into the nucleus where they form the integrated provirus.

It is assumed that reverse transcription is triggered by the exposure of the viral complex to non-limiting deoxyribonucleotides in the cytoplasm [44]. Reverse transcription involves firstly the formation of the minus strand strong-stop DNA, a strand transfer event, and the synthesis of the minus strand DNA with concomitant degradation of the RNA template. In the HIV-1 genome, two polypurine tracts (PPT), the central PPT (cPPT) and 3' PPT, resist degradation by RNase $\mathrm{H}$ and serve as primers for synthesis of plus-strand DNA $[49,53,54]$. Reverse transcription proceeds with synthesis of plus-strand DNA, involves a second strand transfer event, and terminates at a central termination sequence 


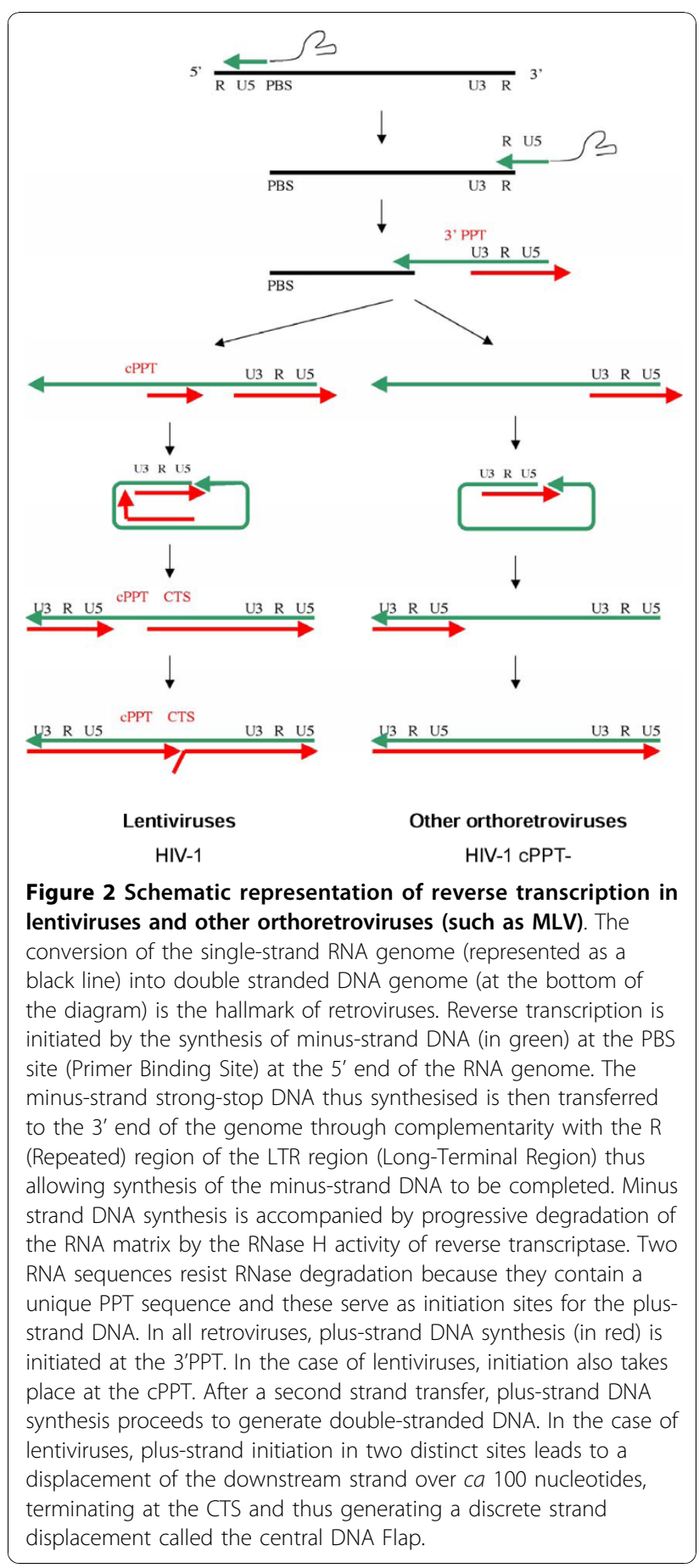

(CTS) in the centre of the genome. The initiation of plus-strand synthesis at the cPPT, as well as the 3' PPT common to all retroviruses, leads to a discrete plusstrand displacement of $c a 100$ nucleotides in the centre of the genome (Figure 2). The final product of HIV-1 reverse transcription is therefore a linear doublestranded DNA with a central DNA Flap [54]. The duration of reverse transcription varies according to the metabolic state of the cell and in the case of asynchronous infection. Full-length linear DNA may be detected as early as $4 \mathrm{~h}$ post-infection but reaches its peak at 8-12 h post-infection $[22,55,56]$. Upon DNA Flap formation and completion of reverse transcription, the viral complex becomes a PIC, competent for import into the nucleus and integration within the host cell chromatin.

In the PIC, the $\sim 9.7 \mathrm{~kb} \mathrm{HIV-1}$ genome, which would per definition measure up to $3.3 \mu \mathrm{m}$, is compacted into a $56 \mathrm{~nm}$ diameter object [31], possibly by viral and/or cellular proteins that additionally could render it karyophilic for passage through the nuclear pore. Although the complete identification of PIC components remains elusive due to the difficulty to isolate PICs from infected cells, many viral and cellular factors have been identified as PIC components [34]. PICs are devoid of detectable CA proteins [30,31] and contain IN [30]. The presence of other viral proteins such as NC, matrix (MA), RT and $\mathrm{Vpr}$ is a source of debate [28-31,37]. Several cellular factors have also been shown to associate with HIV-1 PICs, such as the high mobility group protein HMG I (Y) [31] and LEDGF/p75 [57]. Although interaction of these cellular factors with HIV-1 PICs may occur in the cytoplasm, their role in HIV-1 infection becomes apparent in the nucleus where they may assist tethering of the PIC to the chromatin, determine integration site selection and assist integration $[31,58,59]$.

Clearly, the transition between RTC and PIC is associated with uncoating, however the fragile nature of the HIV-1 capsid and the complexity of the early phases of HIV-1 infection have made it particularly difficult to pinpoint when this occurs.

\section{Experimental hurdles to studying the fate of HIV-1 capsids in newly infected cells}

The most straightforward way to study uncoating in infected cells is to isolate RTCs at given time points post-infection using sedimentation velocity gradients and to probe for co-sedimentation of $\mathrm{CA}$ with the viral genome; or conversely to immunoprecipitate cellular extracts with anti-CA antibodies and probe for viral genome by PCR. Using these approaches, CA was not found to be substantially associated with the viral genome within the cytoplasm of infected cells, thus leading to the conclusion that the viral capsid is discarded from RTCs rapidly after cell entry [28,29,37-39]. However, the HIV-1 capsid is inherently unstable and disassembles readily in the presence of non-ionic detergents and upon ultracentrifugation $[2,60]$. Moreover the size, shape and components of isolated RTCs are highly dependent on the conditions used for isolation, particularly on the detergent and salt concentrations [44]. Therefore, it cannot be excluded that the complexes analysed by biochemical isolation 
approaches have in fact lost their capsid during the isolation procedure.

A further difficulty comes from the fact that most incoming viral complexes are more likely to be destined for degradation than on a productive pathway for infection since over $85 \%$ of viruses that have entered the cell do not form proviruses [61]. This is the case of viral particles that have entered by endocytosis [62] and of functional RTCs that are lost in the routing process towards the nucleus [42]. As a result, the majority of cytoplasmic RTCs isolated early after infection likely represent complexes that were damaged or engaged in a pathway of degradation at the time of isolation or observation.

In order to circumvent the need to isolate RTCs from infected cells, some groups have attempted to visualise HIV-1 capsids by in situ ultrastructural electron microscopy in infected cells. Generally speaking however, it is difficult to follow the fate of viral complexes inside the cytoplasm using morphological criteria in sections of electron microscopy (EM) [63]. Indeed, a single viral capsid would be almost impossible to distinguish from other cytoplasmic components unless it was fortuitously cut right along the length of the capsid, thus displaying its unusual conical morphology. Any other cut will lead to heterogeneous circular and ovoid structures. Furthermore, the visualisation of intracellular capsids within a $60 \mathrm{~nm}$ thick EM slice, which represents less than 1:50 ${ }^{\text {th }}$ of the cell thickness, is per definition a rare event. Using this ultrastructural approach with TEM, few [47] or no [40] intact virus cores were observed in the cytoplasm of infected cells.

The intrinsic difficulty of studying HIV-1 uncoating has driven the development of alternative approaches. Using in situ immunohistochemical approaches, HIV-1 CA is readily detected throughout the cytoplasm of infected cells and co-localises with the viral genome $[42,47]$. Nevertheless, in order to demonstrate that this CA signal corresponds to capsid cores rather than soluble CA, immunolabelling of CA or detection of the viral genome must be combined with ultrastructural observations. This is especially difficult to achieve using TEM since preparations generally favour either ultrastructural observations or immunolabelling. One approach to overcome this involves detection of the viral DNA using in situ hybridisation with electron microscopy [64] without the usual protease treatment in order to preserve proteinaceous structures as much as possible. Using this approach, capsid shells could be detected around the viral genome but with weak intensity [47]. An alternative approach involves observing intracellular complexes, in situ via a scanning EM (SEM), in cells stripped of their plasma membrane $[47,65]$. This ultrastructural approach may be readily combined with immunolabelling and may enable the observation of intracellular HIV-1 capsids, identified by specific anti-CA labelling and a morphology similar to intact viral cores [47] (Figure 1).

To study uncoating in a quantitative manner, particulate (intact) capsids may be separated from soluble (monomeric) CA by ultracentrifugation of virions through a sucrose cushion overlaid with a low concentration of detergent [66]. This cell-free assay enabled to analyse the effects of mutations on capsid stability $[14,67,68]$ and of reverse transcription on capsid integrity [47]. A variation of this assay enables the study of capsid uncoating in infected cells by carefully designed ultracentrifugation of cell lysates through a sucrose cushion, which separates cytosolic cores from soluble CA [69]. This fate-of-capsid assay has been used for example to establish a correlation between retroviral restriction and accelerated uncoating $[69,70]$, to study capsid stability in infected cells [71], and quantify retroviral restriction potency and kinetics [72,73].

Given the complexity and fragile nature of the HIV-1 capsids, there is still a need for sensitive, specific and reliable assays for uncoating. No assay may be relied upon solely when interpreting uncoating events.

\section{Timely uncoating is key for HIV-1 reverse transcription, nuclear import and infectivity} Lessons from retroviral restriction: premature uncoating leads to abortive infection

The tripartite motif 5 -alpha (TRIM5 $\alpha$ ) protein is a dominant factor of intrinsic immunity that mediates cellular restriction against retroviral infections in a speciesspecific manner $[74,75]$ and was originally discovered as a determinant of the resistance of monkey cells to HIV-1 infection [76]. Although the exact mechanisms that lead to virus inactivation by TRIM $5 \alpha$ proteins remain unclear [77], it is known that TRIM5 $\alpha$ targets intact retroviral capsids early in viral replication prior to reverse transcription, by interacting directly with these through its B30.2 (SPRY) C-terminal domain $[69,78,79]$. Interestingly, Fv1 restriction of MLV in mouse cells, although known to involve different mechanisms than TRIM5 $\alpha$, also targets capsid cores [80,81]. Retroviral restriction mechanisms are thought to have evolved in many species including primates as a result of evolutionary pressure exerted by continual exposure to retroviruses [77]. The startling evolutionary conservation of recognition of capsid cores as restriction mechanism suggests that their structure, composition and stability are key to retroviral infections.

In the case of restriction of HIV-1 in rhesus macaque cells, it was originally supposed that TRIM5 $\alpha$ binding might inhibit the uncoating of the viral capsid [82,83], thought to be required for reverse transcription to initiate in the cytoplasm of newly infected cells. However, 
more recent work indicates that TRIM5 $\alpha$, quite on the contrary, promotes the rapid and premature disassembly of viral capsids thus abrogating productive reverse transcription $[69,70,84]$ (Figure 3). These findings indicated for the first time that premature uncoating of HIV-1, far from being beneficial for initiation of reverse transcription and infection, is in fact detrimental to both and is the molecular cornerstone for potent species-specific retroviral restrictions. This suggests that the stability and integrity of HIV-1 capsids during the early steps of infection is key to effective replication. In support of this are findings that capsid mutants with either reduced or increased stability compromise almost systematically HIV-1 infection [14] (Figure 3), indicating that both too rapid and too slow uncoating are detrimental for HIV-1 infection.

\section{Lessons from reverse transcription: unsuccessful reverse transcription precludes uncoating}

One hypothesis proposes that uncoating might occur in response to changes in viral nucleic acid nature and structure, rather than in changes in cellular environment. If this were the case, then inhibiting reverse transcription would be expected to arrest uncoating at a very defined and reproducible step. Strikingly, blocking reverse transcription by a reverse transcriptase inhibitor (Nevirapine) resulted in the accumulation of conical capsid cores in proximity to and at the nuclear membrane and nuclear pores at late time points post-

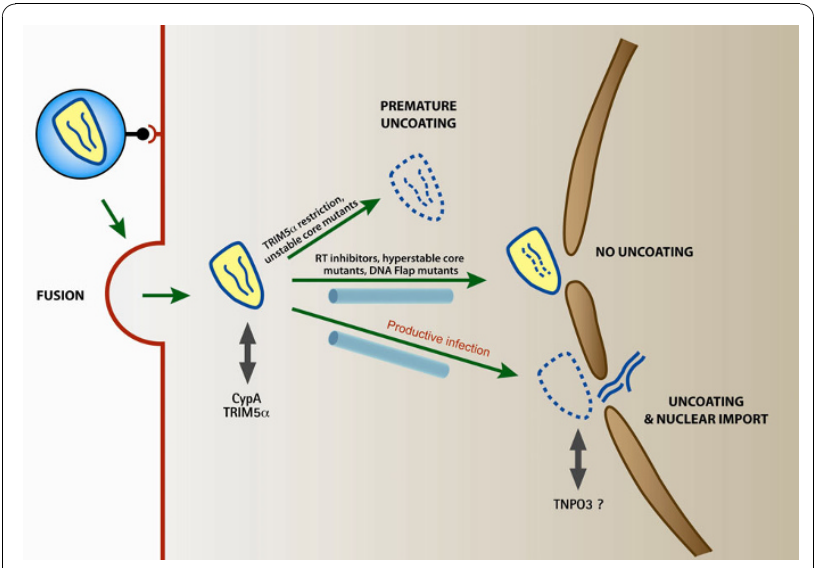

Figure 3 Schematic representation of the fates of viral capsids in the cytoplasm of newly infected cells. After entry into the cytoplasm, HIV-1 capsids that are on a path of productive infection remain intact and are transported towards the nucleus along the cytoskeleton. They uncoat at the nuclear membrane upon completion of reverse transcription. Premature uncoating, in the case of TRIM5 $\alpha$ restriction or of unstable capsid mutants, leads to abortive infection. Similarly, compromised uncoating, in the case of incomplete reverse transcription or of hyperstable capsid mutants, also leads to a dead-end infection event. infection [47]. These were formally identified as HIV-1 capsids based on specific anti-CA labelling and morphological criteria, and were shown to contain the viral genome using EM in situ hybridisation. An accumulation of intact capsids at the nuclear membrane was also observed in the case of inhibition of DNA Flap formation, the last chronological event of reverse transcription [47] (Figure 1). Therefore, although incoming HIV-1 capsids may undergo stepwise destabilisation during cell entry and cytoplasmic transport, these data suggest that HIV-1 uncoating is not progressive but occurs upon completion of reverse transcription. They also suggest that progression through reverse transcription and uncoating is independent of transport towards the nucleus.

\section{Lessons from nuclear import: timely uncoating underlies} the ability of HIV-1 to infect non-dividing cells

The search for the determinants of nuclear import that allow HIV-1 and other lentiviruses to infect nondividing cells is an active and controversial field of investigation [85]. Based on the search of nuclear localization sequences, a number of HIV-1 proteins have been proposed to contribute in a redundant manner to the karyophilic properties of the HIV-1 PIC but the actual participation of these proteins in HIV-1 genome nuclear import has been a matter of strong debate [85]. The integrase protein, which is tightly associated with PICs until the integration of the viral DNA into the host chromosomes, is karyophilic and may participate in HIV-1 nuclear import. The cis-acting sequences cPPT and CTS, which form the central DNA Flap during reverse transcription, have also been identified as determinants of HIV-1 genome nuclear import [22] and are as a result systematically inserted within lentiviral vectors to enhance gene transfer efficiencies.

Intriguingly, recent work based on capsid mutants or chimeras has introduced the existence of a functional link between the HIV-1 CA and nuclear import $[46,48,86]$, underlying the importance of timely uncoating for nuclear import. Furthermore, the requirement of HIV-1 nuclear import for transportin-SR2 [87] [88], also called TNPO3, has been mapped to the HIV-1 CA [89]. Although an interaction between HIV-1 capsid and TNPO3 remains to be demonstrated, a CA point mutation renders HIV-1 insensitive to TNPO3 knockdown [90]. Uncoating is necessary for passage through the nuclear pore, and HIV-1 complexes that fail to uncoat will accumulate at the cytoplasmic face of the nuclear membrane [47]. However, these data further suggest that HIV-1 CA may also be essential to mediate interaction with the nuclear pore, with transport proteins such as transportin-SR2, or with nucleoporins prior to uncoating. 


\section{Conclusion: rethinking HIV-1 uncoating}

Previous work led us to suppose that the HIV-1 capsid core, although all-essential for initial delivery into the cytoplasm, is then discarded immediately post-fusion to stimulate reverse transcription. Others propose that uncoating probably occurs gradually, possibly in response to multiple cellular cues such as interaction with cellular proteins or subcellular localisation, or viral cues such as the progress of reverse transcription. Although incoming capsids may undergo progressive destabilisation during their transport towards the nucleus, since hyperstable capsid mutants have impaired reverse transcription [14], recent independent experiments suggest that the position and timing of uncoating may in fact be tightly regulated and have a trigger. Uncoating must be neither too early nor too late in order to ensure productive infection (Figure 3).

Although the intricacies of HIV-1 uncoating - its timing, location and mechanism - are by no means resolved, recent work enables us to etch a possible model for the early steps of HIV-1 infection. Entry of HIV-1 into target cells delivers the intact capsid core into the cytoplasm and exposure of the viral nucleoprotein complex to non-limiting deoxyribonucleotides triggers reverse transcription. This likely occurs within the intact capsid core, which is essential for maintaining a high concentration of enzyme around the nucleic acid while being entirely permeable to the necessary deoxyribonucleotides. During reverse transcription, HIV-1 RTCs move rapidly toward the nuclear compartment, using microtubules then actin filaments to reach the nuclear pore $[42,47]$. Since transport to the nuclear pore (within minutes to 1-2 hours) is more rapid than reverse transcription (8-12 hours), it is likely that most viral DNA synthesis occurs within capsid cores docked at the nuclear pore. This implies that subcellular fractionation experiments that do not distinguish between nuclear membrane and nucleoplasm are in fact incapable of distinguishing nuclear from cytoplasmic HIV-1 complexes. Indeed, HIV-1 complexes docked at the nuclear membrane will appear in the nuclear fraction even though they are in fact in the cytoplasm. The presence of intact HIV-1 capsids at the nuclear membrane further implies that the most likely viral structure that interacts with the host cell during transport towards the nucleus is the capsid core. Using a yeast-two-hybrid screen and interaction assays with capsid cores, we identified several components of the microtubule and actin network as interaction partners for HIV-1 capsid and essential cofactors of HIV-1 infection (A. Becker, S. Munier, N. Arhel, unpublished data). Therefore, as well as being essential for reverse transcription, the capsid shell may also be key to bringing viral complexes to their site of replication.

One hypothesis brought forward is that the completion of reverse transcription and the formation of the central DNA Flap trigger or facilitate uncoating [47]. If this is the case, then the trigger for uncoating is not a cellular cue, as is the case for adenoviruses [91] or herpes simplex virus type 1 [92], but a viral signal. Concordant with this, uncoating can occur in vitro upon synthesis of full-length viral DNA by endogenous reverse transcription, suggesting that any cellular factors required for uncoating are present within HIV-1 virions [47]. Apart from the DNA Flap, other viral and cellular factors have been proposed to participate in uncoating, including IN [93], prolyl isomerases Pin1 [94] and Cyclophilin A [72], and cellular factors present in nonresting cells [95].

A further hypothesis is that uncoating occurs at the nuclear pore [47] and allows PICs to be imported into the nucleus. Consistent with this is the fact that CA may constitute a determinant of HIV-1 PIC nuclear import $[46,48,86,89]$. Premature uncoating, as in the case of TRIM5 $\alpha$ restriction or unstable capsid mutants, leads to abortive infection. Similarly, complexes that fail to uncoat, such as hyperstable capsid mutants or in the case of inhibited reverse transcription, cannot be imported into the nucleus.

Much of previous work was interpreted in light of the assumption that HIV-1 uncoating occurred immediately post-fusion and the association of CA with intracellular HIV-1 was understood to be detrimental for HIV-1 infection. If we accept the premise that HIV-1 capsids uncoat at the nuclear pore upon completion of reverse transcription, our interpretation of data must be reversed: the loss of capsid cores after entry then corresponds to early degradation products of abortive complexes and the maintaining of intact capsids to complexes on the path of productive infection.

\section{Perspectives}

The molecular mechanisms underlying the destabilisation and uncoating of HIV-1 in the cytoplasm of infected cells remain to be elucidated. Both cytoplasmic environment and major rearrangements of the RTC at the end of reverse transcription could contribute to the disassembly of capsids prior to nuclear import. Furthermore, the importance of timely uncoating for HIV-1 infection and the fact that the capsid is the target of evolutionary conserved anti-retroviral restriction mechanisms emphasise the interest to develop a new class of anti-retroviral drugs that either accelerate or entirely inhibit uncoating. 


\section{Acknowledgements}

The author thanks the CNRS (Centre National de Recherche Scientifique), the ANRS (Agence Nationale de Recherche sur le SIDA), the FRM (Fondation pour la Recherche Médicale) and the Pasteur Institute for financial support, Pierre Charneau and the members of his lab for helpful discussions, and Sylvie Souquere-Besse for her expertise in electron microscopy. Apologies are extended to those colleagues whose studies could not be mentioned due to space limitation.

\section{Competing interests}

The author declares that they have no competing interests.

Received: 7 September 2010 Accepted: 17 November 2010

Published: 17 November 2010

\section{References}

1. Höglund S, Ofverstedt LG, Nilsson A, Lundquist P, Gelderblom H, Ozel M, Skoglund U: Spatial visualization of the maturing HIV-1 core and its linkage to the envelope. AIDS Res Hum Retroviruses 1992, 8:1-7.

2. Welker R, Hohenberg H, Tessmer U, Huckhagel C, Kräusslich HG Biochemical and structural analysis of isolated mature cores of human immunodeficiency virus type 1. J Virol 2000, 74:1168-1177.

3. Briggs JA, Wilk T, Welker R, Kräusslich HG, Fuller SD: Structural organization of authentic, mature HIV-1 virions and cores. EMBO J 2003, 22:1707-1715.

4. Benjamin J, Ganser-Pornillos BK, Tivol WF, Sundquist WI, Jensen GJ: Threedimensional structure of HIV-1 virus-like particles by electron cryotomography. J Mol Biol 2005, 346:577-588.

5. Ganser BK, Li S, Klishko VY, Finch JT, Sundquist WI: Assembly and analysis of conical models for the HIV-1 core. Science 1999, 283:80-83.

6. Li S, Hill CP, Sundquist WI, Finch JT: Image reconstructions of helical assemblies of the HIV-1 CA protein. Nature 2000, 407:409-413.

7. Ganser-Pornillos BK, Cheng A, Yeager M: Structure of full-length HIV-1 CA: a model for the mature capsid lattice. Cell 2007, 131:70-79.

8. Pornillos O, Ganser-Pornillos BK, Kelly BN, Hua Y, Whitby FG, Stout CD, Sundquist WI, Hill CP, Yeager M: X-ray structures of the hexameric building block of the HIV capsid. Cell 2009, 137:1282-1292.

9. Vogt VM: Retroviral virions and genomes.Edited by: Coffin JM, Hughes $\mathrm{SH}$, Varmus HE. Cold Spring Harbor, N.Y: Cold Spring Harbor Laboratory Press; 1997:27-69.

10. Wiegers K, Rutter G, Kottler H, Tessmer U, Hohenberg H, Krausslich HG: Sequential steps in human immunodeficiency virus particle maturation revealed by alterations of individual Gag polyprotein cleavage sites. J Virol 1998, 72:2846-2854.

11. Krausslich HG, Facke M, Heuser AM, Konvalinka J, Zentgraf H: The spacer peptide between human immunodeficiency virus capsid and nucleocapsid proteins is essential for ordered assembly and viral infectivity. J Virol 1995, 69:3407-3419.

12. Li F, Goila-Gaur R, Salzwedel K, Kilgore NR, Reddick M, Matallana C, Castillo A, Zoumplis D, Orenstein JM, Allaway GP, Freed EO, Wild CT: PA-457: a potent HIV inhibitor that disrupts core condensation by targeting a late step in Gag processing. Proc Natl Acad Sci USA 2003, 100:13555-13560.

13. Zhou J, Yuan X, Dismuke D, Forshey BM, Lundquist C, Lee KH, Aiken C, Chen $\mathrm{CH}$ : Small-molecule inhibition of human immunodeficiency virus type 1 replication by specific targeting of the final step of virion maturation. J Virol 2004, 78:922-929.

14. Forshey BM, von Schwedler U, Sundquist WI, Aiken C: Formation of a human immunodeficiency virus type 1 core of optimal stability is crucial for viral replication. J Virol 2002, 76:5667-5677.

15. Gartner S, Markovits P, Markovitz DM, Betts RF, Popovic M: Virus isolation from and identification of HTLV-III/LAV-producing cells in brain tissue from a patient with AIDS. JAMA 1986, 256:2365-2371.

16. Weinberg JB, Matthews TJ, Cullen BR, Malim MH: Productive human immunodeficiency virus type 1 (HIV-1) infection of nonproliferating human monocytes. J Exp Med 1991, 174:1477-1482.

17. Bukrinsky MI, Sharova N, Dempsey MP, Stanwick TL, Bukrinskaya AG, Haggerty S, Stevenson M: Active nuclear import of human immunodeficiency virus type 1 preintegration complexes. Proc Natl Acad Sci USA 1992, 89:6580-6584.

18. Roe T, Reynolds TC, Yu G, Brown PO: Integration of murine leukemia virus DNA depends on mitosis. EMBO J 1993, 12:2099-2108.
19. Bowerman B, Brown PO, Bishop JM, Varmus HE: A nucleoprotein complex mediates the integration of retroviral DNA. Genes Dev 1989, 3:469-478.

20. Katz RA, Greger JG, Boimel P, Skalka AM: Human immunodeficiency virus type 1 DNA nuclear import and integration are mitosis independent in cycling cells. J Virol 2003, 77:13412-13417.

21. König R, Zhou Y, Elleder D, Diamond TL, Bonamy GM, Irelan JT, Chiang CY, Tu BP, De Jesus PD, Lilley CE, Seidel S, Opaluch AM, Caldwell JS, Weitzman MD, Kuhen KL, Bandyopadhyay S, Ideker T, Orth AP, Miraglia LJ, Bushman FD, Young JA, Chanda SK: Global analysis of host-pathogen interactions that regulate early-stage HIV-1 replication. Cell 2008, 135:49-60.

22. Zennou V, Petit C, Guetard D, Nerhbass U, Montagnier L, Charneau P: HIV-1 genome nuclear import is mediated by a central DNA flap. Cell 2000, 101:173-85.

23. Bouyac-Bertoia M, Dvorin JD, Fouchier RA, Jenkins Y, Meyer BE, Wu LI, Emerman M, Malim MH: HIV-1 infection requires a functional integrase NLS. Mol Cell 2001, 7:1025-1035.

24. Ao Z, Yao X, Cohen EA: Assessment of the role of the central DNA flap in human immunodeficiency virus type 1 replication by using a singlecycle replication system. J Virol 2004, 78:3170-3177.

25. Arhel N, Munier S, Souque P, Mollier K, Charneau P: Nuclear import defect of human immunodeficiency virus type 1 DNA flap mutants is not dependent on the viral strain or target cell type. J Virol 2006, 80:10262-10269

26. Fuller BG: Self-organization of intracellular gradients during mitosis. Cell Div 2010, 5:5.

27. Kalab P, Heald R: The RanGTP gradient - a GPS for the mitotic spindle. J Cell Sci 2008, 121:1577-1586

28. Karageorgos L, Li P, Burrell C: Characterization of HIV replication complexes early after cell-to-cell infection. AIDS Res Hum Retroviruses 1993, 9:817-823.

29. Iordanskiy S, Berro R, Altieri M, Kashanchi F, Bukrinsky M: Intracytoplasmic maturation of the human immunodeficiency virus type 1 reverse transcription complexes determines their capacity to integrate into chromatin. Retrovirology 2006, 3:4

30. Farnet $C M$, Haseltine WA: Determination of viral proteins present in the human immunodeficiency virus type 1 preintegration complex. J Virol 1991, 65:1910-1915.

31. Miller MD, Farnet CM, Bushman FD: Human immunodeficiency virus type 1 preintegration complexes: studies of organization and composition. J Virol 1997, 71:5382-5390.

32. Bukrinsky M: A hard way to the nucleus. Mol Med 2004, 10:1-5.

33. Lehmann-Che J, Saiib A: Early stages of HIV replication: how to hijack cellular functions for a successful infection. AIDS Rev 2004, 6:199-207.

34. Suzuki Y, Craigie R: The road to chromatin - nuclear entry of retroviruses. Nat Rev Microbiol 2007, 5:187-196.

35. Dvorin JD, Malim MH: Intracellular trafficking of HIV-1 cores: journey to the center of the cell. Curr Top Microbiol Immunol 2003, 281:179-208.

36. Mortuza GB, Haire LF, Stevens A, Smerdon SJ, Stoye JP, Taylor I: Highresolution structure of a retroviral capsid hexameric amino-termina domain. Nature 2004, 431:481-485.

37. Bukrinsky Ml, Sharova N, McDonald TL, Pushkarskaya T, Tarpley WG, Stevenson M: Association of integrase, matrix, and reverse transcriptase antigens of human immunodeficiency virus type 1 with viral nucleic acids following acute infection. Proc Natl Acad Sci USA 1993, 90:6125-6129.

38. Heinzinger NK, Bukinsky MI, Haggerty SA, Ragland AM, Kewalramani V, Lee MA, Gendelman HE, Ratner L, Stevenson M, Emerman M: The Vpr protein of human immunodeficiency virus type 1 influences nuclear localization of viral nucleic acids in nondividing host cells. Proc Natl Acad Sci USA 1994, 91:7311-7315

39. Fassati A, Goff SP: Characterization of intracellular reverse transcription complexes of human immunodeficiency virus type 1. J Virol 2001 75:3626-3635.

40. Grewe C, Beck A, Gelderblom HR: HIV: early virus-cell interactions. J Acquir Immune Defic Syndr 1990, 3:965-974.

41. Warrilow D, Tachedjian G, Harrich D: Maturation of the HIV reverse transcription complex: putting the jigsaw together. Rev Med Virol 2009, 19:324-337.

42. McDonald D, Vodicka MA, Lucero G, Svitkina TM, Borisy GG, Emerman M, Hope TJ: Visualization of the intracellular behavior of HIV in living cells. J Cell Biol 2002, 159:441-452. 
43. Nermut MV, Fassati A: Structural analyses of purified human immunodeficiency virus type 1 intracellular reverse transcription complexes. J Virol 2003, 77:8196-8206.

44. Goff SP: Intracellular trafficking of retroviral genomes during the early phase of infection: viral exploitation of cellular pathways. J Gene Med 2001, 3:517-528.

45. Klarmann GJ, Schauber CA, Preston BD: Template-directed pausing of DNA synthesis by HIV-1 reverse transcriptase during polymerization of HIV-1 sequences in vitro. J Biol Chem 1993, 268:9793-9802.

46. Dismuke DJ, Aiken C: Evidence for a functional link between uncoating of the human immunodeficiency virus type 1 core and nuclear import of the viral preintegration complex. J Virol 2006, 80:3712-3720.

47. Arhel NJ, Souquere-Besse S, Munier S, Souque P, Guadagnini S, Rutherford S, Prévost MC, Allen TD, Charneau P: HIV-1 DNA Flap formation promotes uncoating of the pre-integration complex at the nuclear pore. EMBO J 2007, 26:3025-3037.

48. Yamashita M, Perez O, Hope TJ, Emerman M: Evidence for direct involvement of the capsid protein in HIV infection of nondividing cells. PLOS Pathog 2007, 3:1502-1510.

49. Telesnitsky A, Goff SP: Reverse transcriptase and the generation of retroviral DNA. In Retroviruses. Edited by: Coffin JM, Hughes SH, Varmus HE. Cold Spring Harbor, N.Y: Cold Spring Harbor Laboratory Press; 1997:121-160.

50. Basu VP, Song M, Gao L, Rigby ST, Hanson MN, Bambara RA: Strand transfer events during HIV-1 reverse transcription. Virus Res 2008, 134:19-38

51. Ellison V, Abrams $H$, Roe T, Lifson J, Brown P: Human immunodeficiency virus integration in a cell-free system. J Virol 1990, 64:2711-2715.

52. Farnet $C M$, Haseltine WA: Integration of human immunodeficiency virus type 1 DNA in vitro. Proc Natl Acad Sci USA 1990, 87: 4164-4168.

53. Charneau P, Alizon M, Clavel F: A second origin of DNA plus-strand synthesis is required for optimal human immunodeficiency virus replication. J Virol 1992, 66:2814-2820.

54. Charneau P, Mirambeau G, Roux P, Paulous S, Buc H, Clavel F: HIV-1 reverse transcription. A termination step at the center of the genome. $J \mathrm{Mol} B \mathrm{Bi} /$ 1994, 241:651-662.

55. Kim SY, Byrn R, Groopman J, Baltimore D: Temporal aspects of DNA and RNA synthesis during human immunodeficiency virus infection: evidence for differential gene expression. J Virol 1989, 63:3708-3713.

56. Barbosa P, Charneau P, Dumey N, Clavel F: Kinetic analysis of HIV-1 early replicative steps in a coculture system. AIDS Res Hum Retroviruses 1994, 10:53-59.

57. Llano M, Vanegas M, Fregoso O, Saenz D, Chung S, Peretz M, Poeschla EM: LEDGF/p75 determines cellular trafficking of diverse lentiviral but not murine oncoretroviral integrase proteins and is a component of functional lentiviral preintegration complexes. J Virol 2004, 78:9524-9537.

58. Emiliani S, Mousnier A, Busschots K, Maroun M, Van Maele B, Tempé D, Vandekerckhove L, Moisant F, Ben-Slama L, Witvrouw M, Christ F, Rain JC, Dargemont C, Debyser Z, Benarous R: Integrase mutants defective for interaction with LEDGF/p75 are impaired in chromosome tethering and HIV-1 replication. J Biol Chem 2005, 280:25517-25523.

59. Ciuffi A, Llano M, Poeschla E, Hoffmann C, Leipzig J, Shinn P, Ecker JR, Bushman F: A role for LEDGF/p75 in targeting HIV DNA integration. Nat Med 2005, 11:1287-1289.

60. Borroto-Esoda K, Boone LR: Equine infectious anemia virus and human immunodeficiency virus DNA synthesis in vitro: characterization of the endogenous reverse transcriptase reaction. J Virol 1991, 65:1952-1959.

61. Thomas JA, Ott DE, Gorelick RJ: Efficiency of human immunodeficiency virus type 1 postentry infection processes: evidence against disproportionate numbers of defective virions. J Virol 2007, 81:4367-4370.

62. Maréchal V, Clavel F, Heard JM, Schwartz O: Cytosolic Gag p24 as an index of productive entry of human immunodeficiency virus type $1 . J$ Virol 1998, 72:2208-2212

63. Risco C, Menéndez-Arias L, Copeland TD, Pinto da Silva P, Oroszlan S: Intracellular transport of the murine leukemia virus during acute infection of NIH 3T3 cells: nuclear import of nucleocapsid protein and integrase. J Cell Sci 1995, 108:3039-3050.

64. Arhel NJ, Souquere-Besse S, Charneau P: Wild-type and central DNA flap defective HIV-1 lentiviral vector genomes: intracellular visualization at ultrastructural resolution levels. Retrovirology 2006, 3:38
65. Allen TD, Rutherford SA, Murray S, Gardiner F, Kiseleva E, Goldberg MW, Drummond SP: Visualization of the nucleus and nuclear envelope in situ by SEM in tissue culture cells. Nat Protoc 2007, 2:1180-1184.

66. Aiken C: Cell-free assays for HIV-1 uncoating. Methods Mol Biol 2009, 485:41-53

67. Wacharapornin P, Lauhakirti D, Auewarakul P: The effect of capsid mutations on HIV-1 uncoating. Virology 2007, 358:48-54.

68. Brun S, Solignat M, Gay B, Bernard E, Chaloin L, Fenard D, Devaux C, Chazal N, Briant L: VSV-G pseudotyping rescues HIV-1 CA mutations that impair core assembly or stability. Retrovirology 2008, 5:57.

69. Stremlau M, Perron M, Lee M, Li Y, Song B, Javanbakht H, Diaz-Griffero F, Anderson DJ, Sundquist WI, Sodroski J: Specific recognition and accelerated uncoating of retroviral capsids by the TRIM5alpha restriction factor. Proc Natl Acad Sci USA 2006, 103:5514-5519.

70. Perron MJ, Stremlau M, Lee M, Javanbakht H, Song B, Sodroski J: The human TRIM5alpha restriction factor mediates accelerated uncoating of the N-tropic murine leukemia virus capsid. J Virol 2007, 81:2138-2148.

71. Li Y, Kar AK, Sodroski J: Target cell type-dependent modulation of human immunodeficiency virus type 1 capsid disassembly by cyclophilin A. J Virol 2009, 83:10951-10962.

72. Javanbakht H, Diaz-Griffero F, Yuan W, Yeung DF, Li X, Song B, Sodroski J: The ability of multimerized cyclophilin $A$ to restrict retrovirus infection. Virology 2007, 367:19-29.

73. Diaz-Griffero F, Kar A, Lee M, Stremlau M, Poeschla E, Sodroski J: Comparative requirements for the restriction of retrovirus infection by TRIM5alpha and TRIMCyp. Virology 2007, 369:400-410.

74. Nisole S, Stoye JP, Saïb A: TRIM family proteins: retroviral restriction and antiviral defence. Nat Rev Microbiol 2005, 3:799-808.

75. Towers GJ: The control of viral infection by tripartite motif proteins and cyclophilin A. Retrovirology 2007, 4:40.

76. Stremlau M, Owens CM, Perron MJ, Kiessling M, Autissier P, Sodroski J: The cytoplasmic body component TRIM5alpha restricts HIV-1 infection in Old World monkeys. Nature 2004, 427:848-853.

77. Neil S, Bieniasz P: Human immunodeficiency virus, restriction factors, and interferon. J Interferon Cytokine Res 2009, 29:569-580.

78. Sebastian S, Luban J: TRIM5alpha selectively binds a restriction-sensitive retroviral capsid. Retrovirology 2005, 2:40.

79. Forshey BM, Shi J, Aiken C: Structural requirements for recognition of the human immunodeficiency virus type 1 core during host restriction in owl monkey cells. J Virol 2005, 79:869-875.

80. Goff SP: Retrovirus restriction factors. Mol Cell 2004, 16:849-859.

81. Bieniasz PD: Intrinsic immunity: a front-line defense against viral attack. Nat Immunol 2004, 5:1109-1115.

82. Stevenson M: TRIMming HIV-1's mainsail. Nat Immunol 2004, 5:355-356.

83. Goff SP: HIV: replication trimmed back. Nature 2004, 427:791-793.

84. Black LR, Aiken C: TRIM5alpha disrupts the structure of assembled HIV-1 capsid complexes in vitro. J Virol 2010, 84:6564-6569.

85. Fassati A: HIV infection of non-dividing cells: a divisive problem. Retrovirology 2006, 3:74.

86. Yamashita $M$, Emerman $M$ : Capsid is a dominant determinant of retrovirus infectivity in nondividing cells. J Virol 2004, 78:5670-5678.

87. Brass AL, Dykxhoorn DM, Benita Y, Yan N, Engelman A, Xavier RJ, Lieberman J, Elledge SJ: Identification of host proteins required for HIV infection through a functional genomic screen. Science 2008, 319(5865):921-6

88. Christ F, Thys W, De Rijck J, Gijsbers R, Albanese A, Arosio D, Emiliani S, Rain JC, Benarous R, Cereseto A, Debyser Z: Transportin-SR2 imports HIV into the nucleus. Curr Biol 2008, 18:1192-1202

89. Krishnan L, Matreyek KA, Oztop I, Lee K, Tipper CH, Li X, Dar MJ, Kewalramani VN, Engelman A: The requirement for cellular transportin 3 (TNPO3 or TRN-SR2) during infection maps to human immunodeficiency virus type 1 capsid and not integrase. J Virol 2010, 84:397-406.

90. Lee K, Ambrose Z, Martin TD, Oztop I, Mulky A, Julias JG, Vandegraaff N, Baumann JG, Wang R, Yuen W, Takemura T, Shelton K, Taniuchi I, Li Y, Sodroski J, Littman DR, Coffin JM, Hughes SH, Unutmaz D, Engelman A, KewalRamani VN: Flexible use of nuclear import pathways by HIV-1. Cell Host Microbe 2010, 7:221-233.

91. Trotman LC, Mosberger N, Fornerod M, Stidwill RP, Greber UF: Import of adenovirus DNA involves the nuclear pore complex receptor CAN/ Nup214 and histone H1. Nat Cell Biol 2001, 3:1092-1100. 
92. Ojala PM, Sodeik B, Ebersold MW, Kutay U, Helenius A: Herpes simplex virus type 1 entry into host cells: reconstitution of capsid binding and uncoating at the nuclear pore complex in vitro. Mol Cell Biol 2000, 20:4922-4931.

93. Briones MS, Dobard CW, Chow SA: Role of human immunodeficiency virus type 1 integrase in uncoating of the viral core. J Virol 2010, 84:5181-5190

94. Misumi S, Inoue M, Dochi T, Kishimoto N, Hasegawa N, Takamune N, Shoji S: Uncoating of human immunodeficiency virus type 1 requires prolyl isomerase Pin1. J Biol Chem 2010, 285:25185-25195.

95. Auewarakul P, Wacharapornin P, Srichatrapimuk S, Chutipongtanate S, Puthavathana P: Uncoating of HIV-1 requires cellular activation. Virology 2005, 337:93-101.

doi:10.1186/1742-4690-7-96

Cite this article as: Arhel: Revisiting HIV-1 uncoating. Retrovirology 2010 7:96.

Submit your next manuscript to BioMed Central and take full advantage of:

- Convenient online submission

- Thorough peer review

- No space constraints or color figure charges

- Immediate publication on acceptance

- Inclusion in PubMed, CAS, Scopus and Google Scholar

- Research which is freely available for redistribution

Submit your manuscript at www.biomedcentral.com/submit 